\title{
Estratégias de mobilização comunitária, redes e resistências
}

\author{
Community mobilization strategies, networks and resistance \\ Estrategias de movilización comunitaria, redes y resistencias
}

Antenora Siqueira ${ }^{1}$

\section{Resumo}

SIQUEIRA, Antenora et al. Estratégias de mobilização comunitária, redes e resistências. Rev.C\&Trópicos, v. 45, n.2, p. 221-236, 2021. DOI: https://doi.org/10.33148/cetropicov45n2(2021)art14

O artigo apresenta questões relativas aos processos de luta e resistência vivenciados por lideranças comunitárias brasileiras. Deu-se ênfase às estratégias utilizadas para a mobilização de sujeitos individuais e/ou coletivos - notadamente moradores dos lugares em que vivem ou viviam -, bem como às redes formadas, que delas fazem parte e seus objetivos. O conteúdo empírico do texto é oriundo dos depoimentos elaborados e apresentados pelas lideranças no II Seminário de Desnaturalização dos Desastres e Mobilização. Foi possível evidenciar que as estratégias são diversificadas e criativas, entre elas: 1) sensibilização e engajamento das pessoas mais próximas para ações diversas, incluindo elaboração de blogs e manifestações; 2) ampliação desse coletivo com a adesão de aliados institucionais na elaboração de estudos, jornais, vídeos e projetos para obtenção de recursos; 3) apresentação dos pleitos e projetos aos órgãos públicos e corporações, e 4) estruturação de redes.

Palavras-chave: Mobilização social. Conflito. Racismo ambiental. Risco.

\section{Abstract}

SIQUEIRA, Antenora et al. Community mobilization strategies, networks, and resistance. Rev. C\&Trópicos, v. 45, n.2, p. 221-236, 2021. DOI: https://doi.org/10.33148/cetropicov45n2(2021)art14

This article addresses issues regarding the fight and resistance processes experienced by Brazilian community leaders. The strategies were emphasized for mobilizing individual and/or collective subjects - particularly residents of the places where they live or used to live - along with the networks formed, which are part of them, and their goals. The empirical content of the text originates from statements made and presented by the leaders at the II Seminar on Denaturalization of Disasters. It was evidenced that the strategies are diverse and creative, among them: 1) awareness and engagement of the closest people for various actions, including creation of

1 Docente do Programa de Pós-graduação em Desenvolvimento Regional, Ambiente e Políticas Públicas da Universidade Federal Fluminense, Brasil. E-mail: antenoras@id.uff.br e antenorams@gmail.com Orcid: https://orcid.org/0000-0002-9844-3701 
blogs, and demonstrations; 2) increase of this group with the joining of institutional allies in the development of studies, newspapers, videos, and projects for obtaining resources; 3) presentation of demands and projects to public bodies and corporations, 4) networking.

Keywords: Social mobilization. Conflict. Environmental racism. Risk.

\section{Resumen}

SIQUEIRA, Antenora et al. Estrategias de movilización comunitaria, redes y resistencias. Rev. C\&Trópicos, v. 45, n.2, p. 221-236, 2021. DOI: https://doi.org/10.33148/cetropicov45n2(2021)art14

El artículo plantea aspectos relacionados con los procesos de lucha y resistencia vividos por los líderes comunitarios brasileños. El artículo plantea aspectos relacionados con los procesos de lucha y resistencia vividos por los líderes comunitarios brasileños. El énfasis se centra en las estrategias utilizadas para la movilización de los sujetos individuales y/o colectivos -sobre todo los residentes de los lugares donde viven o vivían-, así como en las redes formadas, quiénes las integran y sus objetivos. El contenido empírico del texto resulta de los testimonios preparados y presentados por los líderes en el II Seminario de Desnaturalización de los Desastres. Se pudo constatar que las estrategias son diversas y creativas, entre otras: 1) sensibilización y compromiso de las personas más cercanas por varias acciones, incluyendo la creación de blogs y manifestaciones; 2) ampliación de este grupo con la adhesión de aliados institucionales en la realización de estudios, periódicos, videos y proyectos para obtener recursos; 3) presentación de las reivindicaciones y proyectos a los organismos públicos y corporaciones, 4) estructuración de redes.

Palabras clave: Movilización social. Conflicto. Racismo ambiental. Riesgo. 


\section{Introdução}

As sucessivas experiências com desastres, desastres-crimes, catástrofes e conflitos socioambientais têm suscitado ações dos sujeitos individuais e coletivos nelas imbricados, especialmente em uma conjuntura nacional marcada por crises política, econômica, ambiental, sanitária e social. Em tal contexto, nota-se que o Estado tem se associado aos agentes econômicos para viabilização de projetos de interesse desses dois segmentos, enquanto uma parcela majoritária da população põe em ação diferentes formas de luta por direitos não consolidados, mesmo que preconizados na constituição brasileira de 1988, e em legislações específicas e complementares.

A mesa Estratégias de mobilização comunitária, redes e resistência foi um dos espaços de troca de experiências entre quatro lideranças comunitárias e os demais participantes do II Seminário Internacional de Desnaturalização dos Desastres e Mobilização Comunitária, ocorrido remotamente neste ano de 2021, devido à pandemia da Covid-19. O espaço destinado às estratégias de mobilização não foi o único em que se contemplou o protagonismo popular: as lideranças de movimentos sociais, associações e coletivos participaram da oficina sobre mudanças climáticas; mulheres de vários coletivos populares estiveram na oficina sobre interseccionalidade e grandes empreendimentos, e uma liderança quilombola e outra indígena compuseram a mesa de encerramento do seminário e falaram sobre "como adiar o fim do mundo".

Uma boa parte da literatura nacional sobre mobilização social a associa aos movimentos sociais (GOHN, 2013; TORO; WERNECK, 2007). Entretanto, no seminário aqui citado e neste texto, foram considerados os vários processos de mobilização no cotidiano e suas estratégias - das redes de vizinhança aos movimentos sociais. Mobilização diz respeito à sensibilização, articulação e engajamento de sujeitos em coletivos tanto para uma ação política de cunho reivindicatório, contestatório e/ou propositivo como também para lidar com situações emergenciais.

O texto contempla uma síntese dos quatro casos apresentados no Seminário. O primeiro se refere à luta das(dos) quilombolas, pescadoras(es) da Ilha de Maré em Salvador/Bahia contra megaempreendimentos. Na sequência, o processo de mobilização e resistência dos atingidos do bairro do Caleme, em Teresópolis/Rio de Janeiro, que deu origem à organização da Associação de Vítimas de Teresópolis (AVIT), cuja luta se dá em torno da ausência dos governos em relação às moradias danificadas por ocasião da catástrofe de 2011. O terceiro é outro caso ocorrido na região serrana do estado do Rio de Janeiro, decorrente da catástrofe de 2011: a luta dos atingidos e a mobilização da Associação de Moradores de Córrego D’Antas em Nova Friburgo. A seguir, será apresentado o caso do jornal A Sirene, ferramenta criada após o rompimento da barragem de Fundão, das mineradoras Samarco/Vale/BHP em Mariana, Minas Gerais, como estratégia de mobilização voltada para dar voz aos atingidos, publicizar e socializar a perspectiva desses sujeitos diante da grande mídia e da opinião pública. 


\section{Do lixo invisível à lama marron}

A apresentação desse caso se deu em dois momentos: o primeiro foi com um documentário sobre o lixo industrial em Ilha de Maré, e o segundo, um depoimento sobre o processo de mobilização, luta e resistência dos sujeitos da Ilha por seus direitos em seu lugar de vida e trabalho. ${ }^{2}$

\subsection{O documentário apresentado - Assassino invisível: lixo industrial em Ilha de Maré}

A produção do audiovisual se deu a partir de uma prática de mobilização e luta utilizada pelas mulheres da Ilha da Maré desde 2018, o toque soturno, que consiste em sair de barco para identificar e mostrar o que ameaça os territórios das águas da Ilha e o seu entorno, bem como destacar o potencial existente nas comunidades. Inspirada nessa prática, organizou-se uma expedição com mulheres pescadoras da Ilha de Maré, produzida pela Mídia Ninja, com apoio da Fiocruz e do CES/Universidade de Coimbra.

As frases a seguir, estampadas no documentário, e aqui reproduzidas em itálico, dão visibilidade a questões que não são novas, mas são fundamentais para a luta quando produzidas em um vídeo que possa denunciar nas esferas nacional e internacional.

Noventa por cento dos moradores da Ilha vivem da pesca. O que irão fazer se não puderem mais pescar?

A Ilha de Maré foi cercada pelo complexo industrial e pelo porto de Aratu.

São vários empreendimentos localizados em cinco municípios cujos dejetos atingem a Baía de Todos os Santos e, consequentemente, a Ilha de Maré. São eles: São Francisco do Conde, onde está a refinaria Landulpho Alves; Madre de Deus, onde está localizado um porto da Transpetro; Simões Filho que abriga todo o complexo industrial do polo petroquímico; Candeias onde está situado o porto de Aratu, responsável por escoar uma boa parte da produção química e petroquímica e passará a receber a produção de grãos do oeste baiano e de outras regiões; e Salvador que abriga empreendimentos diversificados. Muitos dejetos, incluindo o lixo tóxico de algumas empresas são lançados na Baía de Todos os Santos. As frases que virão a seguir figuram também como denúncia que o vídeo apresenta.

Os poluentes despejados na Baía de Todos os Santos causam prejuízos irreparáveis em toda forma de vida. Estudos atualizados detectaram altos niveis de Cádmio e Chumbo no sangue das crianças da Ilha

O depoimento da pescadora ML ilustra o estranhamento relacionado às substâncias químicas e a ameaça ao seu modo de vida percebido por várias gerações da família:

a gente nunca ouviu falar, por exemplo, em Cádmio, em Chumbo, em Mercúrio. A gente nunca ouvir falar em propeno, ibuprofeno (...) A gente nunca tinha ouvido falar disso. Então essas

2 Quilombolas marisqueiras, pescadoras e pescadores de Ilha de Maré/Salvador/Bahia e os grandes empreendimentos. 
coisas não são nossas. Pai conta que meu bisavô, o avô dele, vô Cândido, quando viu o Porto de Aratu chegar ele dizia: acabou a vida da gente, acabou a saúde da gente. E vô Cândido tava certo porque realmente tem diminuído muito a vida da gente, $o$ tempo de vida da gente (ML,2019).

A pesquisa foi realizada em 2006 pela UFBA, mas não reconhecida pelos representantes governamentais como prova.

A próxima frase apresentada detalha o percentual de atingidos identificado na pesquisa:

Em algumas regiões da Ilha, mais de $90 \%$ das crianças pesquisadas apresentaram altos níveis de contaminação.

A filha de EP é uma das meninas que foram pesquisadas e veio a falecer, vítima de câncer, como expresso na frase em destaque após este parágrafo. Muitos atualmente são adolescentes e jovens e a perda de A abalou a esperança em transformar a situação para que outras gerações tenham a saúde garantida.

"A morreu com 13 anos de câncer no ombro e com complicações no fígado."

O depoimento da mãe de A no documentário afirma a desigualdade e a dificuldade de lutar contra algo que não se vê como a poluição/contaminação por produtos químicos.

Devido a isso, a estratégia precisou contar com novos parceiros que pudessem realizar pesquisas e comprovar a presença das substâncias químicas, como foi feito pela UFBa. Mais que isso, também para fortalecer os movimentos, a essa altura já tão combatidos e criminalizados pelo poder público associado às empresas, conforme depoimento a seguir:

[...] o que a gente tem vivenciado aqui na Bahia é isso e a criminalização dos movimentos. A gente enfrenta (...) por a gente defender o mangue, as coroas e as áreas que a gente pesca. A gente é criminalizado com polícia na porta com "direito" a ser preso, com direito a pagar $2 \backslash 3$ do ano pagando cesta básica porque você defendeu o direito de sobreviver, você defendeu o direito da sua comunidade, você defendeu o direito de uma classe que sempre sobreviveu daquilo que faz, que é a pesca, que é o pescado, que é alimento que a gente produz e que movimenta essa Bahia com o que a gente faz (EP, 2019).

\subsection{As reflexões após o vídeo: Os "vários braços do racismo"}

O depoimento da liderança após o término da exibição do documentário foi iniciado com uma afirmação sobre a existência do racismo ambiental ${ }^{3}$ e o racismo

3 Racismo ambiental: $\mathrm{O}$ conceito diz respeito às injustiças sociais e ambientais que recaem de forma desproporcional sobre etnias vulnerabilizadas. Diz respeito a um tipo de desigualdade e de injustiça ambiental muito específico: o que recai sobre suas etnias, bem como sobre todo grupo de populações di- 
político em Ilha de Maré. Eles se desagregam e mostram "seus vários braços: o racismo na educação, na alimentação e na saúde".

Em 2016, foi realizada uma pesquisa que constatou que 116 crianças estavam contaminadas por metais pesados no sangue: chumbo, cádmio e mercúrio. Em 2021, essas crianças já eram adultas, entre 21 e 22 anos, e algumas delas vieram a óbito. Ilha de Maré conta com uma população que tem um número alarmante de casos de câncer, e casos com traços de anemia falciforme.

Como visto no conteúdo do vídeo, a pesquisa da UFBa foi contestada pelo Estado que não buscou ouvir a população sobre o que estava passando. E quando o coletivo de moradores consegue discutir a questão com representantes do executivo municipal, eles negam e não tentam identificar o que atingidos vivenciam. Tampouco associam as mortes ocorridas na Ilha da Maré com a poluição química gerada pelos empreendimentos. Com isto as lutas não cessam, mesmo porque as mulheres lideranças da localidade continuam sendo ameaçadas de prisão e morte, além de receberem multas.

\subsection{As estratégias de luta e mobilização}

A luta não tem só uma estratégia de mobilização. São várias.

Inicialmente, "a mobilização social dos nossos corpos", por meio das ocupações na BR-101 (rodovia federal que corta o Estado da Bahia), nas secretarias de governo, no porto e em qualquer lugar. "Quando entendemos que alguém vai assinar a sentença de morte do nosso povo, a gente partia pra cima".

Depois houve "a mobilização do audiovisual", valorizado por conseguir chegar "em lugares que os nossos pés ainda não pisaram" e dar visibilidade "ao racismo ambiental nos corpos das mulheres das águas e da população povo preto" no Brasil e em muitos outros países.

A mobilização de instituições parceiras levou a buscar a Fiocruz numa verdadeira "peregrinação que a gente começou na Bahia, chega no Rio, chega em outros países e de lá consegue chegar na Fiocruz do Rio de Janeiro". O resultado foi positivo, uma vez que profissionais da Fundação têm estado no território da Ilha de Maré realizando pesquisa para verificar a(s) causa(s) do elevado número de mortes por câncer naquele lugar. Buscou-se, nessa ação, um laudo que os moradores possam apresentar como prova, uma vez que o governo negou o resultado da pesquisa de 2006 da UFBa, além de divulgar na Câmara que a comunidade é contrária ao desenvolvimento do Estado. Na percepção dos moradores o governo é aliado dos empresários, e a luta de mais de duas décadas é para barrar o que chamam de "injustiça profunda".

tas tradicionais - ribeirinhos, extrativistas, geraizeiros, pescadores, pantaneiros, caiçaras, vazanteiros, ciganos, pomeranos, comunidades de terreiro, faxinais, quilombolas etc. - que têm se defrontado com a 'chegada do estranho', isto é, de grandes empreendimentos desenvolvimentistas - barragens, projetos de monocultura, carcinicultura, maricultura, hidrovias e rodovias - que os expelem de seus territórios e desorganizam suas culturas, seja empurrando-os para as favelas das periferias urbanas, seja forçando-os a conviver com um cotidiano de envenenamento e degradação de seus ambientes de vida e trabalho. (HERCULANO, 2006, p.16) 
A Ilha de Maré é um “território saudável e sustentável, que tem uma diversidade linda", mas que "é sitiada por 21 poços de petróleo, sendo sete no território pesqueiro e 14 no território quilombola" (EP, 2021). Nem mesmo os royalties são reinvestidos na Ilha para atender às prioridades dos moradores que reivindicam a sua aplicação na saúde, na educação em uma política diferenciada para a alimentação, em especial neste período de pandemia da Covid-19.

$\mathrm{Na}$ perspectiva da liderança, o documentário apresenta alguns aspectos da luta desigual dos quilombolas pela sua sobrevivência contra os representantes do capital (megaempreendimentos) e o racismo ambiental que lhes é imposto.

\section{A Associação de Moradores do Caleme, Teresópolis/Rio de Janeiro e a questão da moradia após catástrofe de 2011.4}

\subsection{Contexto}

O bairro do Caleme se localiza em Teresópolis, na região serrana ${ }^{5}$ do estado do Rio de Janeiro. Em 2010, o município contava com 163.746 habitantes e densidade demográfica de 212,49 hab $/ \mathrm{km}^{2}$ (IBGE, 2010)

Em 2011, o Caleme e vários outros de Teresópolis foram atingidos pela tragédia. Só nesse bairro 37 pessoas vieram a óbito, foi uma noite aterrorizante para todos os moradores. Foi algo inesperado. "Veio uma chuva muito forte, choveu muito e quando foi na madrugada do dia 12 janeiro de 2011, veio uma onda gigante, uma nuvem enorme onde ela descarregou e destruiu vários bairros” (LS, 2021)

A população sofreu muito sem água, sem luz, muitos perderam suas casas. Alguns ficaram pelas ruas, outros foram para abrigo, outros para casa de familiares.

\subsection{Estratégias de mobilização luta e resistência}

O tempo foi passando e os governantes não faziam nada. Depois de dois meses sem respostas para aqueles sérios problemas, um grupo de pessoas se reuniu e criou a - Associação de Vítimas de Teresópolis (Avit), uma associação para cuidar das vítimas do desastre.

As ações iniciais foram o acolhimento às vítimas. Se fosse necessário, contava-se com psicólogos, com médicos e advogados voluntários para a atenção básica naquele momento.

Com a convivência, viu-se que muitos não tinham onde morar. A Avit entrou com uma ação no Ministério Público para que o grupo conseguisse que a prefeitura pagasse aluguel social, o que foi concedido. Também fez (e faz) parte da luta a conquista

4 Lucinéia da Silva (Presidente da Associação de Moradores do Caleme e diretora da Associação de Vítimas de Teresópolis (AVIT))

5 A região Serrana possui 16 municípios, com uma população de 873.837 habitantes, representando 5,3\% da população total do estado. A região é composta pelos seguintes municípios: Bom Jardim, Cachoeira de Macacu, Cantagalo, Carmo, Cordeiro, Duas Barras, Guapimirim, Macuco, Nova Friburgo, Petrópolis, Santa Maria Madalena, São José do Rio Preto, São Sebastião do Alto, Sumidouro, Teresópolis e Trajano de Moraes (BRASIL, 2007). 
da moradia, uma vez que o aluguel social era algo provisório. Começou com a compra do terreno no bairro Ermitage e a construção de 1600 unidades $^{6}$. Quinhentas famílias ainda não conseguiram entrar nesse processo.

$\mathrm{Na}$ época da tragédia, a pior parte foi o descaso do governo porque os bairros que foram atingidos ficaram abandonados. Aquela população que perdeu suas casas, saiu do bairro; mas a que permaneceu no bairro também ficou no esquecimento.

Foi uma luta muito grande, muitas perdas, até hoje ficou o cenário da tragédia: aquelas casas que foram destruídas ainda permanecem no local porque não foram demolidas. Ainda tem pessoas no aguardo para receber a sua indenização, porque na época da tragédia eram três opções: a compra assistida, a indenização em dinheiro e o apartamento. Em 2013, o governador Sérgio Cabral fez um decreto proibindo a compra assistida e a indenização em dinheiro, ficando só o apartamento. Essa atitude do governador causou uma confusão enorme com os atingidos, porque várias pessoas tinham assinado um acordo para receber a indenização em dinheiro ou uma casa na compra assistida.

Ainda hoje (2021) essas pessoas não conseguiram nada e não sabem se irão conseguir. Mas a luta continua e a Associação vai continuar lutando por eles também, porque a tragédia aconteceu há dez anos, mas ainda tem o reflexo dela. As pessoas ainda existem e elas precisam de ajuda na conquista dos seus direitos. $O$ desastre ainda não terminou.

Porque a tragédia aconteceu em 2011, mas o reflexo dela atinge até hoje porque toda vez que chove é um desespero. Há uma barragem de água enorme no Caleme, só que é uma barragem que os próprios moradores não usam aquela água. A água utilizada para abastecimento doméstico é da CEDAE. Então, há o medo de ocorrer uma chuva forte e essa barragem estourar por falta de manutenção, e se ela estourar vai destruir o bairro inteiro. No desastre de 2011 foi essa barragem que suportou um grande volume de água, serviu como um reservatório.

Essas são algumas das questões. Hoje a luta é para poder reconstruir o bairro com uma vida melhor para a população local. De 2011 até hoje muito foi feito e conquistado pela luta.

Depois que a comunidade fez esse projeto junto com a Fiocruz no Caleme em 2019, a gente está caminhando bem. É o projeto "do nosso território sabemos nós". Através desse projeto a comunidade criou um mapa e dentro desse mapa, com a participação dos moradores, foram colocados todos os problemas relacionados ao bairro desde a tragédia de 2011. Problemas ligados à educação, saúde, questão ambiental, lixo, tudo foi colocado no mapa. Com ele pronto, o grupo fez o projeto e está conseguindo tudo que consta nele.

Hoje a Associação é recebida pelo governo atual porque durante seis anos Teresópolis teve sete prefeitos e nenhum deu jeito na situação desde a tragédia. As parcerias que ajudaram à época: a diocese de Petrópolis, as igrejas católicas, a Cáritas, a Fiocruz, além de outras.

6 Apartamentos do Programa Minha Casa Minha Vida, específico para casos de desastres, com critérios definidos pelo governo federal para as famílias que perderam suas casas, atestado pela defesa civil, com reserva de $10 \%$ dos apartamentos para idosos e portadores de necessidades especiais, com teto de renda definido. 
Em 2019, a Defesa Civil do município criou o Núcleo de Proteção e Defesa Civil (NUPDEC) com moradores do Caleme. Há também ações com a Secretaria de Meio Ambiente e a Secretaria de Saúde, esta última com atendimento em uma unidade móvel (ônibus) que atende no bairro. Há projeto para instalação de um posto de saúde em uma casa naquele local. Outra ação é em parceria com o Horto de Teresópolis em que os moradores estão reflorestando o bairro. Foram plantadas em torno de cinquenta mudas, número que irá aumentar porque o projeto inclui as nascentes, que são muitas nas montanhas do entorno do bairro e que ficaram abandonadas após a tragédia. São trabalhos decorrentes do mapa social feito junto à Fiocruz.

Há uma luta permanente da comunidade junto aos parceiros para conseguir reconstruir o bairro.

\section{A Associação de Moradores de Córrego D’Antas, Nova Friburgo/ Rio de Janeiro e as políticas públicas de recuperação da catástrofe de $2011^{7}$}

\section{1. $O$ contexto}

O bairro Córrego D’Antas está situado em Nova Friburgo, na região serrana do estado do Rio de Janeiro. É um bairro periférico, onde está localizado o prédio da Associação com o centro sociocultural. No plano diretor do município o bairro é apontado como área de expansão por estar próximo à uma rodovia que liga Friburgo a Teresópolis.

A associação de moradores foi fundada em 29 de janeiro de 1987, tendo como presidente o Sr. João Cuzats, que já mobilizava os moradores há algumas décadas. A partir dessa mobilização é que o bairro foi construído e urbanizado, conquistando com muita luta os serviços públicos de direito da comunidade.

Um período importante, mesmo que muito difícil para quem vive no bairro, foi quando ocorreu o desastre socioambiental de 11 de janeiro de 2011. Foi um desastre que afetou diversos municípios da região serrana do estado do Rio de Janeiro, com maior gravidade Petrópolis, Teresópolis e Friburgo. Em Córrego D’Antas, estima-se que morreram cerca de trinta pessoas e é possível declarar que houve uma síntese dos fenômenos decorrentes daquela intensa chuva. Ocorreram avalanches de pedras, quedas de barreira, enxurradas, inundações e grandes perdas também, além das perdas de vidas, muita gente foi ferida e a infraestrutura do bairro toda afetada: fornecimento de luz, água, a paisagem ficou comprometida, o rio foi totalmente assoreado e teve o seu curso alterado. Foi um cenário muito pavoroso.

Os moradores se depararam com uma realidade inimaginável: um bairro destruído. O que se ouvia daqueles que chegaram do centro da cidade, da mídia e mesmo do poder público é que o bairro tinha acabado. Para os governantes o bairro não existia mais e o que sobrou teria que sair dali. Essas orientações assustaram os que se mantinham no local, incluindo o atual presidente da Associação (que não era presidente

7 Sandro Schottz (Presidente da Associação de Moradores de Córrego D’Antas). 
na época) que procurou dirigentes da associação de moradores para buscar ajuda com alguns secretários municipais. Entretanto, nem mesmo os secretários tinham como agir porque a prefeitura também passava por um momento crítico politicamente. $\mathrm{O}$ prefeito tinha se acidentado e assumiu o interino. Dada a gravidade da situação, houve necessidade de contar com o governo do Estado, o que levou o vice-governador Pezão à região serrana para assumir a prefeitura e a gestão de crise juntamente com as forças armadas, defesa civil e empresários.

Diante da ameaça de ter que sair do bairro, os moradores tinham uma decisão a ser tomada: assumir que o bairro acabou, recolher o que sobrou e partir; ou organizar as pessoas, "arregaçar as mangas" e reconstruir o bairro. A opção foi de ficar e lutar.

\subsection{As estratégias de luta e mobilização}

Os moradores marcavam encontros e se organizavam em reuniões frequentes. Dada a gravidade da situação, passaram a se reunir semanalmente, com a presença de muitas pessoas do bairro e de colaboradores externos. Nesses encontros, colhiam e viabilizavam ideias: mutirões para limpar a rua, uma vez que o poder público ainda não fazia o serviço, e a elaboração de um blog para divulgar o que acontecia.

As ações ganharam uma grande visibilidade, o que contribuiu para facilitar o atendimento pelo prefeito para convidá-lo para o mutirão. A reunião no seu gabinete foi viabilizada e ele aceitou o convite para o mutirão, ao qual compareceu com uma equipe da Prefeitura. A partir de então, começou a acontecer algo positivo no bairro não só para retratar o ocorrido, mas também para saber que movimento era esse, quem eram essas pessoas, essa comunidade que estava se organizando, indo para rua. Os moradores atingidos começaram a ganhar força política através desse movimento.

O jornal mais importante da região se tornou um parceiro daquela época, noticiando tudo o que acontecia juntamente com o site da Associação. A ação seguinte foi lotar a câmara de vereadores com a comunidade para falar das questões dos moradores e do bairro.

Uma dessas questões foi a creche. Ela estava desativada, com muitas mães perdendo emprego por não terem com quem deixar as crianças durante o período do trabalho. A ocupação da secretaria de educação, com grupos de mulheres e crianças atendidas pela creche reivindicando a reabertura, resultou na conquista de uma creche provisória.

Foram quatro anos de luta para que chegassem as obras do estado e do município: pontes, obras de contenção, drenagem, calçamento das ruas.

Faltava outra ação importante: as casas que deveriam ser desocupadas. Ressaltase que o mapa de desocupação foi muito questionado e gerou crise. Os moradores ainda estavam contabilizando os mortos e chega o projeto de um parque fluvial que a comunidade sequer foi consultada, não teve nenhuma audiência pública para ouvir a Associação e os moradores. Isso gerou uma crise com o poder público.

Foram muitas crises, infelizmente as coisas não foram fáceis. O que mais contribuiu nesse processo todo foi conseguir um poder de mobilização muito grande, se não fosse isso, provavelmente o bairro teria acabado. E muita força houve para que o bairro acabasse, mas o coletivo conseguiu algo a mais, que foi a construção do nosso 
centro sociocultural. Batizado com o nome do Sebastião Shottz (foi quem doou o terreno), o prédio foi construído com recurso do governo e da população do Cantão de Friburgo (Canton de Fribourg)/Suíça.

\subsection{A rede formada}

Após inaugurado o Centro Sociocultural Sebastião Shottz, muitas pessoas estão mobilizadas também em torno da saúde, das atividades esportivas, artes marciais, festas, eventos diversos e reuniões.

O trabalho permanente na área levou a parcerias com organizações comunitárias, instituições de pesquisa e órgãos de governo que, de modo participativo, culminaram na elaboração de planos e projetos importantes para o bairro. Essas parcerias desaguam para essa grande rede da bacia do Córrego d'Antas que é a Reger-CD - Rede de Gestão de Riscos da Bacia Hidrográfica de Córrego d’Antas.

Para isso tudo acontecer é fundamental a mobilização. É esse o tema tratado aqui: a mobilização das pessoas para gestão de risco. O trabalho realizado no bairro deu muita visibilidade às ações, à Associação e à Rede, o que fez a organização ser procurada por grupos que queriam implementar projetos, que reconheciam que havia um nível razoável de organização com condições de mobilizar as pessoas para um determinado projeto.

É importante esclarecer que, às vezes, a mobilização não é algo constante e as pessoas envolvidas não estão sempre presentes. $\mathrm{Na}$ fase mais crítica sim, estavam. Depois que se conseguiu organizar o bairro, houve um processo de desmobilização. Há o chamado para as reuniões e, às vezes, não dá o mesmo número de pessoas de antes, outras vezes só tem a diretoria. Em contrapartida, quando se faz uma festa o número de pessoas aumenta. Esse posicionamento envolve uma série de questões que precisam ser pensadas.

As reflexões aumentaram a necessidade de tentar entender um pouco mais quais são as questões que envolvem a mobilização para as ações de gestão de risco. Por exemplo, se realiza o exercício do simulado de desocupação de áreas de risco pela defesa civil e não funciona porque as pessoas não comparecem. Por meio da Reger foram realizadas ações para discussão e elaboração de um plano de contingência e, com muito custo, se conseguiu alguma participação, mas muito aquém do potencial existente no bairro. Considerando a dimensão das comunidades, deveria ter uma mobilização que levasse a uma participação muito maior, mas se vê que é muito difícil. Faz parte de processos como esse.

Pelo dicionário (Aurélio) se vê que mobilizar é dar movimento, movimentar, pôr em movimento. $\mathrm{O}$ termo mobilização historicamente foi vinculado a ações militares, $\mathrm{o}$ que pode ser verificado no conceito de Monteiro, que foi chefe da divisão de assuntos de mobilização na Escola Superior de Guerra. Para ele mobilizar é "dar movimento, pôr em movimento ou circulação, fazer passar do estado de paz para o estado de guerra”. Esse conceito se aplica ao meio militar que se pauta na hierarquia, na disciplina e na obediência. Para a gestão no meio civil o conceito anterior não é apropriado, e o autor cita que o termo começou a ser cunhado em outras áreas: sociologia, economia, entre outras, para falar de mobilização dos trabalhadores, mobilização de recursos. 
Ao continuar a busca pelas definições, identificou-se a publicação de Toro e Werneck, que conceituam a mobilização como "um processo de convocação de vontades para uma mudança realidade através de propósito em comum estabelecido em consenso" (TORO; WERNECH, 2007).

A motivação que aconteceu em Córrego D’Antas, na época da tragédia, foi a motivação intrínseca, que parte de fatores internos das pessoas da comunidade. $\mathrm{Ou}$ seja, a liderança não mobilizou ninguém, as pessoas se mobilizaram naquele momento pela urgência, pela necessidade. Então, enquanto mobilizadores, queremos partir da identificação para chegar nesse ponto da motivação intrínseca que é onde os projetos ganham autonomia. Eles se autorregulam, ganham autodeterminação, as pessoas caminham com e nos projetos, não precisam de alguém externo para mobilizar.

Alguns fatores que dificultam a mobilização é a qualidade democracia, democracia de procedimento: você ter eleição, você tem alguns espaços de participação, mas que não alcançam a dimensão social mais ampla. A garantia dos direitos no sistema político-governamental muitas vezes gera desconfiança, perpetua mazelas como fisiologismo, patrimonialismo, corporativismo. Isso tudo vai gerando uma desconfiança que prejudica a mobilização e consequente participação social.

\section{Jornal A Sirene ${ }^{8}$}

\subsection{O contexto}

O jornal A Sirene é um jornal fundado pela sociedade civil do município de Mariana/MG, após o rompimento da barragem', para dar voz aos atingidos. A intenção era fazer algo que pudesse levar esse sofrimento das vítimas para a mídia, visto que as grandes mídias, na maioria das vezes, dão muito mais ênfase às empresas do que aos atingidos. Então, quando se criou o jornal, buscou-se ter mais uma ferramenta de luta nessa árdua luta contra os grandes empreendimentos.

Para viabilizar o jornal impresso, distribuído gratuitamente, era necessário conseguir recurso para financiá-lo. Um projeto foi feito e entregue à arquidiocese de Mariana, que havia recebido das dioceses brasileiras um valor em dinheiro para administrar, a ser usado em favor dos atingidos. Criou-se um conselho que verificou que não dava para dividir os recursos para todos os atingidos, pois daria uma quantia irrisória para cada família. Decidiu-se financiar projetos, e um dos projetos foi o jornal A Sirene que já existia, mas passou a ser mantido com esse dinheiro.

O jornal tem versões digital e impressa, distribuída nas cidades de Mariana (sede e distritos) e Barra Longa. A sua periodicidade é mensal. É feito por atingidos com assessoria de profissionais da área. $\mathrm{O}$ autor do conteúdo desta parte do artigo é

8 Sergio Papagaio (Editor do jornal A Sirene e membro da Comissão de atingidos de Barra Longa/Minas Gerais)

9 O rompimento da barragem do Fundão em Mariana, Minas Gerais, pertencente à Mineradora Samarco S.A., uma joint-venture entre a brasileira Vale S.A. e a anglo-australiana BHP Billiton, ocorreu no dia 5 de novembro de 2015. A carga de rejeitos atingiu distritos de Mariana e outros municípios à jusante (dentre outras publicações, maiores detalhes nos vários números de A Sirene e no livro de Milanez e Losekann, 2016). 
um dos editores (também um atingido), por isso o texto será na primeira pessoa do singular a partir do próximo parágrafo.

Antes do rompimento da barragem eu era, entre outras coisas, vendedor ambulante na área onde houve o rompimento da barragem. Já conhecia as pessoas, entrava nas casas das pessoas e após o rompimento da barragem de Fundão eu comecei a levar o jornal para essa área atingida e entregar para as pessoas. E tem um fato muito interessante que, em uma dessas entregas eu deixei o jornal com uma pessoa da família, fiz uma reportagem com eles e fui embora. Na outra semana voltei e perguntei para eles: vocês gostaram da reportagem? Aí a senhora disse assim, "nós não sabe ler não Papagaio".

Então, eu peguei o jornal e li para eles. Os moradores sabiam o dia que eu passava para entregar o jornal. Começou a juntar outras pessoas que também não sabiam ler para que eu lesse o jornal para eles. Começamos a perceber que o jornal A Sirene estabeleceu uma relação com essas pessoas não de um jornal propriamente, mas de uma relação familiar, deixamos de ser informação e passamos a ser comunicação. A gente levava informação e trazia informação e essas pessoas começaram a ver que o jornal fazia parte da vida deles, que quando eles abriam o jornal quem estava era o compadre Zé Adão, era Dona Chiquinha, era Sr. Francisco, era Tião do Córrego do Ouro, eram as pessoas que eles conheciam, esse jornal passou a ser família para eles. A partir de então eles começaram a entender que naquele lugar eles podiam falar o que quisessem, eles podiam expor a verdade e que a pessoa do jornal fazia parte da família deles.

O jornal A Sirene é um jornal que sempre esteve também na luta pela regeneração do Rio Doce, nós fizemos parte do movimento "regenera Rio Doce" e "acontece na foz do Rio Doce". É muito importante a gente lembrar que, agora voltando a Eliete, da Ilha de Maré, que fala que ela é mulher das águas, é muito importante a gente lembrar que pra regenerar esse planeta, nós temos que regenerar os rios, regenerar as águas, mas antes nós precisamos regenerar o fluxo de água que corre dentro de cada um de nós. Que todos nós somos afluentes desse rio.

Assim, o jornal é parte do movimento de recuperação, que luta para que as empresas sejam obrigadas a restaurar os danos. Eu ainda sonho um dia que a justiça coloque a Vale e as mineradoras no seu devido lugar, no banco dos réus e deixem com que os atingidos sejam vítimas porque, muitas vezes, formam uma inversão de valores muito grande que acabam colocando os atingidos como réus.

Outra vez eu me reporto a Eliete, dizendo que ela levou multa, isso também acontece na nossa região. Eu tenho um bordão que diz assim: se eu fechar os olhos e for transportado para qualquer lugar da bacia, e ouvir as queixas dos atingidos, eu não saberei dizer onde estou porque as queixas são as mesmas, as negativas de direitos são as mesmas. Hoje eu posso dizer que se eu for transportado para qualquer lugar do Brasil, para qualquer lugar onde tem atingido, eu não saberei dizer onde eu estou porque as queixas continuam sendo as mesmas. Os grandes empreendimentos, as grandes empresas usam as mesmas estratégias para desmobilizar, para dividir e para massacrar a gente, os atingidos.

Por isso, a importância de várias estratégias de luta, e o jornal $A$ Sirene é uma delas. O pessoal começou a confiar no jornal e, hoje, todos eles perguntam: "e o jornal 
vai continuar? Vai acabar?" havendo uma tristeza muito grande entre os atingidos que aprenderam a conviver com esse jornal. Então, é muito importante mantê-lo vivo, porque o jornal é uma ferramenta de luta, ele é parte dessa luta dos atingidos pela reparação.

Essa preocupação é decorrente do fim do recurso administrado pela Diocese para o projeto. Toda equipe está lutando desesperadamente para a sobrevivência do jornal, eu digo que nós estamos sobrevivendo com ajuda de aparelhos e nós tivemos que entregar a sede do jornal, estamos trabalhando de casa, reduzimos nossos próprios salários, todos aceitaram reduzir e passamos a nos manter vivos. Tanto que começamos a campanha de financiamento que ajuda, mas que ainda não é o suficiente. Se não conseguirmos um verdadeiro financiamento com o valor e a frequência necessária o jornal pode acabar.

Quando eu estive no congresso de saúde mental em 2018, eu compus um poema que fala de um aspecto do desastre que tem se repetido muito entre os atingidos de vários lugares: o comprometimento da saúde mental. Foram abordados três assuntos: o incêndio da boate Kiss, o deslizamento na serra do mar [na região serrana do estado do Rio de Janeiro] que está sendo abordado neste artigo, e o rompimento da barragem de Fundão, que eu estou tratando aqui. Vamos a ele:
A Loucura
Tem gente louca dentro do curso
Tem barro quente perto da gente
Boate Kiss fez esquentar
Tem gente louca e não é pouca
É barro doente dentro da mente
Quer me levar, quero voltar
Sua casa não dá para morar
Aqui não quero ficar
Toma essa pílula para melhorar
A minha casa não está lá
A minha menina na boate quis dançar
Debaixo da lama foi morar
Me dê outra pílula para eu tomar
Se tem alguma para eu não lembrar?
Tem gente louca para sua vida reassentar
Em Mariana, em Barra Longa, na serra do mar
A minha vida não foi aqui que eu quis plantar

\section{Considerações finais}

As reflexões sobre as experiências apresentadas nos mostram que as estratégias de mobilização comunitária consistem em um conjunto de ações interligadas, acionadas a depender do contexto e dos sujeitos envolvidos na luta. Diferente das mobilizações iniciadas por agentes externos, na maioria dos casos elas foram iniciadas pelos grupos nas comunidades. 
No caso da Ilha de Maré, as estratégias envolvem a presença dos atingidos em manifestações na rodovia, em ocupações nos órgãos públicos e empresas. Como complemento estão o toque soturno, os vídeos (responsáveis por dar visibilidade às lutas em nível nacional e internacional) e a formação de redes (movimentos sociais, fundações, universidades, ongs).

No Caleme, e em Córrego D’Antas, houve a sensibilização entre vizinhos atingidos para fazerem parte da AVIT e da AMCD, respectivamente. As estratégias também contaram com a criação de espaços para ações coletivas, organização de mutirões, ocupações de espaços do legislativo e executivos municipais, manifestações públicas, criação de mídia ou parceria com as existentes e aliadas para comunicação por meio de site, blog, jornal e estruturação de redes.

Em Barra Longa e Mariana, em Minas Gerais, uma das estratégias utilizadas está no âmbito da comunicação: um jornal que dá voz aos atingidos, com códigos de linguagem do seu cotidiano. É publicado em meio digital e impresso e distribuído para os moradores de várias localidades dos municípios afetados. Destaca-se que há leitores voluntários para aqueles que não sabem ler, iniciativa do editor do jornal que se desdobrou em grupos de leitura e discussão. 


\section{Referências}

GOHN, Maria da Glória. Movimentos Sociais e redes de mobilizações civis no Brasil contemporâneo. Petrópolis-RJ:Vozes, 2013.

MILANEZ, Bruno; LOSEKANN, Cristiana (Orgs). Desastre no Vale do Rio Doce: antecedentes, impactos e ações sobre a destruição. Rio de Janeiro: Folio, 2016.

TORO, José Bernardo; WERNECK, Nísia. Mobilização Social: um modo de construir a democracia e a participação. São Paulo: Autêntica Editora, 2007. 